\title{
Autosomal dominant congenital Horner's syndrome in a Dutch family
}

\author{
G Hageman, P F Ippel, F C A M te Nijenhuis
}

\begin{abstract}
A Dutch family is reported with congenital Horner's syndrome in five cases spanning five generations, with symptoms of varying degree but mainly ptosis and meiosis. Heterochromia iridum, anhidrosis, and enophthalmos were not present. The site of the lesion may be in the region between Gasser's ganglion and the short vertical segment of the internal carotid artery near the siphon. There are only four previous reports showing autosomal dominant inheritance of congenital Horner's syndrome.
\end{abstract}

Horner's syndrome results from interruption of the sympathetic nerve supply to the eye, upper lid, and facial sweat glands at any point in its course. It consists of meiosis due to paralysis of the dilatator pupillae, ptosis due to paralysis of the smooth muscle fibres of the lids, and anhidrosis of the same side of the face caused by involvement of the nerves to the sweat glands. A sympathetic defect proximal to the carotid bifurcation will produce ptosis, meiosis, and ipsilateral facial anhidrosis, whereas a lesion distal to the bifurcation produces ptosis and meiosis without anhidrosis. ${ }^{1}$ Enophthalmos is usually more apparent than real.

Lesions producing Horner's syndrome may occur at any age and may be present at birth. Congenital Horner's syndrome is often due to damage to the cervical sympathetic chain dur-

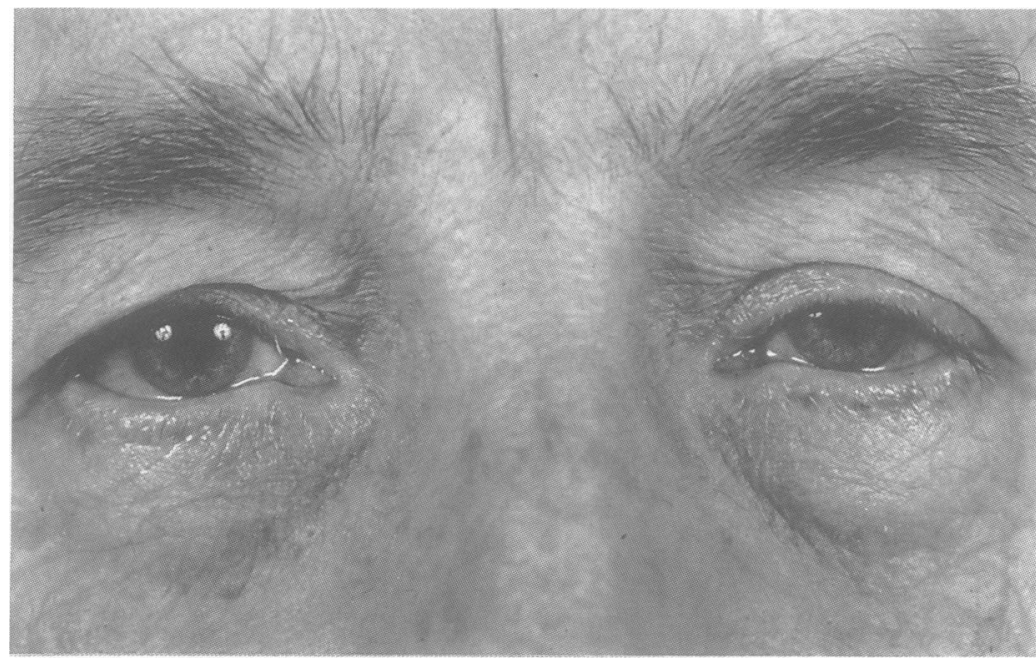

Figure 1 Index case (case IV:8)—mild meiosis and ptosis on the left side. ing a difficult delivery. Congenital Horner's syndrome is usually associated with heterochromia of the iris, the affected side being blue. $^{2}$

Familial congenital Horner's syndrome is very rare. In 1919 Calhoun described a family with congenital Horner's syndrome in five cases spanning three generations. ${ }^{3}$ Later, in 1958, Durham reported five cases in two generations, ${ }^{4}$ demonstrating an autosomal dominant inheritance of congenital Horner's syndrome. ${ }^{5}$ In addition, a brother and sister were described by Gladstone ${ }^{6}$ and a father and son by Mellor et al. ${ }^{7}$ We report a Dutch family with five affected cases spanning five generations.

\section{Case report}

The index case (case IV:8; see figure 2) was a man of 56 who attended the outpatient department two weeks after a sudden onset attack of intense periorbital and supraorbital pain on the left side over three to four hours. There was no visual disturbance or photophobia. Several years before he had an identical headache attack. Examination showed a ptosis on the left side (figure 1), which had been present from an early age, probably from birth. The left pupil was smaller than the right one. Eye colour was equal. There was minimal hyperaemia of the left bulbar conjunctiva. No differences in temperature or moistness were discernible to the touch between the two sides of his face. Corneal reflexes were normal. Enophthalmos was not obvious.

Possible congenital incomplete Horner's syndrome (mainly meiosis and ptosis), was diagnosed. The presence of Horner's syndrome was confirmed by instillation of cocaine into both eyes, increasing pupillary inequality. Doppler investigation of the carotid arteries and brain computed tomography gave normal results. Radiography of the frontal and maxillary sinuses showed signs of a chronic inflammation of the left maxillary sinus, with thickening of the mucosa. This was treated by an otorhinolaryngologist with astringents; to date no more headache attacks have occurred.

The family history showed that the patient's daughter, great-grandfather, and probably grandfather also had a ptosis of one eye.

\section{Family study}

The family consisted of 63 members spanning six generations. One member of the family had 


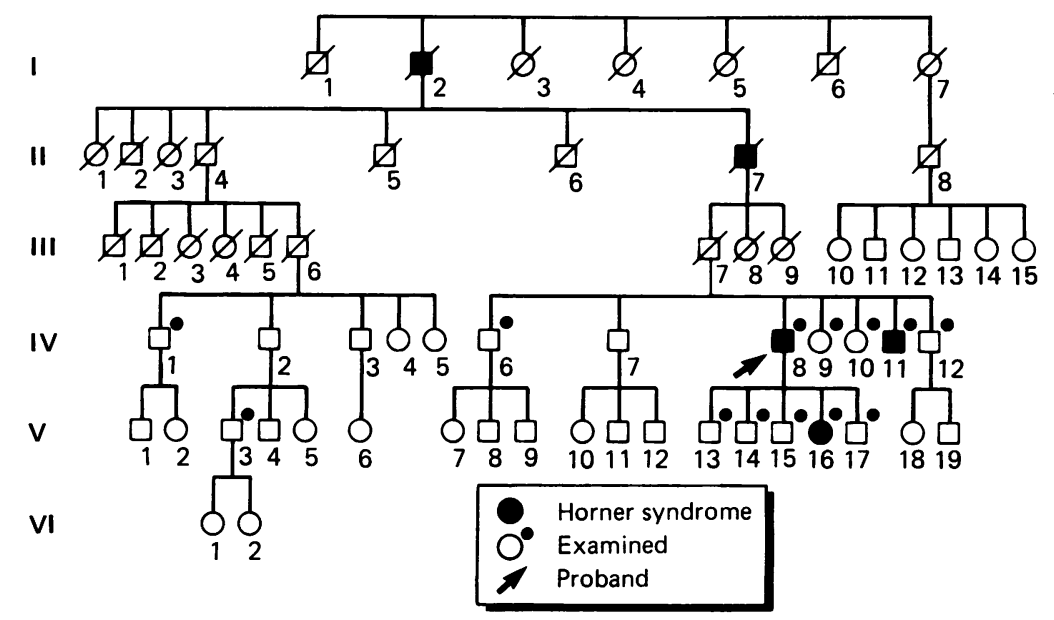

Figure 2 Pedigree.

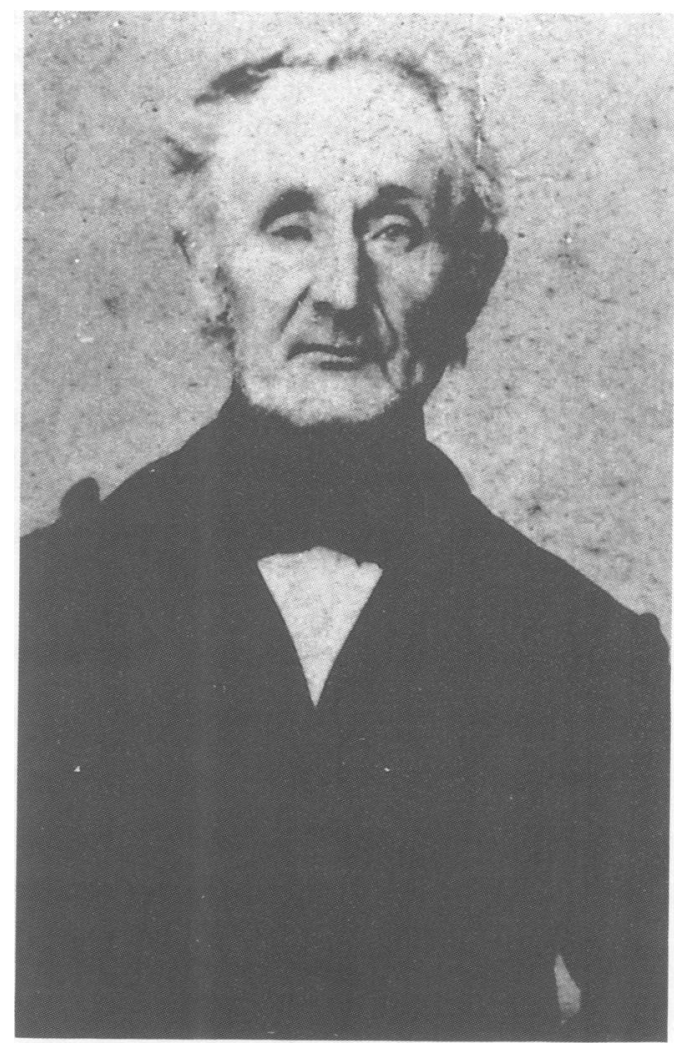

Figure 3 Case I:2-right ptosis.

syndrome could be confirmed (case I.2) This case, the great grandfather of the index case, born in 1820, showed a right ptosis (figure 3).

In the second generation the diagnosis of Horner's syndrome could be excluded in three cases, whereas in one case (II:7) ptosis was probable.

Two cases in the third generation had no signs of Horner's syndrome. Various photographs of the parents of the index case also seemed to be normal. In the fourth generation there was a slight ptosis without meiosis in one brother (case IV:11) of the index case, but there were no signs of Horner's syndrome in the other brothers and sisters, although one (case IV:7) could not be investigated. Photographs of five other cases in the fourth generation seemed to be normal.

Finally, in the fifth generation one daughter of the index case (IV:16) had a right ptosis (figure 4), which had been present from birth,

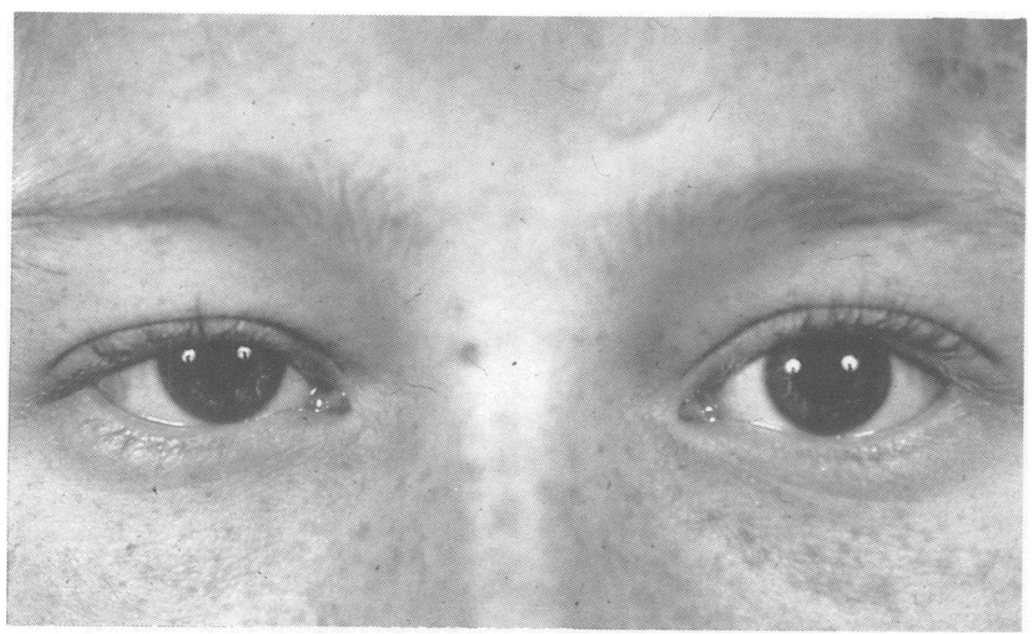

Figure 4 Case V:16-right piosis.

with minimal meiosis and equal coloured eyes. The four other children of the index case showed no signs of Horner's syndrome.

\section{Discussion}

The five affected cases in this family show incomplete Horner's syndrome of varying degree. Meiosis was not visible in the photograph of the great grandfather but may have been present. Meiosis was minimal in case $\mathrm{V}: 16$ and absent in the affected brother of the index case. Although thermography ${ }^{7}$ and quantitative sweat rate measurements ${ }^{8}$ were not performed in our cases, medical history and clinical investigation showed no anhidrosis.

The onset of ptosis could not be traced back in case IV:11. It was present at an early age in our index case and congenital in his daughter. Therefore it is remarkable that heterochromia iridum, although described in all four previously reported families with congenital Horner's syndrome, was not present in our family.

Pigmentation results from melanophores migrating into the iris and choroid under sympathetic influence in the first months of life. ${ }^{3}$ Iris pigmentation is complete about the age of two years. In the case of a congenital sympathetic defect melanin is reduced and the eye appears blue.

The absence of heterochromia iridum in our family may have localising value, indicating only partial involvement of the fibre tracts at the site of the lesion. We suggest that the Horner's syndrome in the index case could be produced only by a middle cranial fossa lesion located between Gasser's ganglion and the short vertical segment of the internal carotid 
artery near the siphon. In this region the ocular sympathetic innervation leaves the internal carotid plexus at various levels in different ramifications. This localisation is also consistent with a Horner's syndrome with meiosis and ptosis, but without anhidrosis and enophthalmos. ${ }^{1}$

Previous reports stated an autosomal dominant pattern of heredity. ${ }^{3-5}$ Autosomal dominant inheritance seems also to be present in our family. A variable expression leads to symptoms in varying degree and probably also explains the switching of the affected side from generation to generation. The relatively few affected cases is probably due to incomplete penetrance.

We thank Dr R P M Bruyn for reviewing the manuscript, Mrs
I P van der Meulen-Mos for typing the manuscript, and Mr P Weise for producing the figures.

1 Spalding JMK. Autonomic nervous system. In: Vinken PJ, Bruyn GW, eds. Handbook of clinical neurology. Vol 2 . Localization in clinical neurology. 1969.

2 Robinson GC, Dikrainian DA, Roseborough GF. Congenital Horner's syndrome and heterochromia iridtum. Pediatrics 1965;35:103-7.

3 Calhoun FP. Causes of heterochromia iridis with special reference to paralysis of the cervical sympathetic. $A m J$ Ophthalmol 1919;2:255-69.

4 Durham DG. Congenital hereditary Horner's syndrome. Arch Ophthalmol 1958;60:939-40.

5 McKusick. Autosomal dominant phenotypes. In: Mendelian inheritance in man. 9th ed. 1990:472.

6 Gladstone RM. Development and significance of heterochromia of the iris. Arch Neurol 1969;21:184-92.

7 Mellor DH, Richardson JE, Watmough D. The use of thermography in familial congenital Horner's syndrome. Dev Med Child Neurol 1973;15:14-8.

8 Saito H. Congenital Horner's syndrome with unilateral facial flushing. J Neurol Neurosurg Psychiatry 1990;
53:85-6. 